\title{
Conceptos sobre inocuidad en la producción primaria de la leche.
}

\section{Food Safety Concepts in Primary Production of Milk}

\author{
Leana Zumbado Gutiérrez ${ }^{1} \bowtie$ y Juan José Romero Zuñiga ${ }^{2}$
}

1 Cátedra de Inspección e Higiene de Alimentos, Escuela de Medicina Veterinaria, Universidad Nacional, Heredia, Costa Rica. Apdo. postal: 304-3000 Heredia. Teléfono: (506) 25624565. leana.zumbado. gutierrez@una.cr

2 Cátedra de Salud de Hato y Control de la Producción, Escuela de Medicina Veterinaria, Universidad Nacional, Heredia, Costa Rica.juan.romero.zuniga@una.cr

Recibido: 28 de Octubre de 2015. Corregido: 11 de Enero de 2016. Aceptado: 19 de Enero de 2016.

Resumen: La producción primaria de la leche es uno de los eslabones más importantes a lo largo de la cadena de producción, tratamiento y manejo de la leche y sus subproductos; así, debe asegurarse que la leche sea producida por animales sanos, bajo óptimas condiciones higiénicas y de manejo, que garanticen un producto inocuo y de calidad. Sin embargo, existen peligros asociados a la producción primaria de la leche que representan riesgos potenciales de causar daño a los consumidores; afortunadamente, pueden ser controlados bajo ciertas regulaciones. Estos peligros pueden ser catalogados como físicos (cuerpos extraños), químicos (pesticidas, antibióticos, micotoxinas, metales pesados o desinfectantes) o microbiológicos (microorganismos patógenos). Al mismo tiempo, de manera complementaria, la industria lechera demanda un producto proveniente de la finca que cumpla estándares deseables de calidad; esto se logra con la aplicación de normas específicas, tanto nacionales como internacionales, que procuren reducir los riesgos a un mínimo aceptable. Entre estas normas se encuentran las emitidas por el Codex Alimentarius y las de la Organización de las Naciones Unidas para la Alimentación y la Agricultura (FAO). Por ende, los productores de leche, así como las asociaciones, cooperativas, industria y gobierno, deben impulsar y verificar la aplicación de medidas de manejo que colaboren a controlar los aspectos que influyen durante la extracción y mantenimiento de la leche.

Palabras clave: Leche, producción primaria, inocuidad, lácteos, peligros

Abstract: Primary production of milk is one of the most important aspects in the chain of production, processing and handling of milk and dairy products. Consequently, producing milk from healthy animals under optimal management and hygienic conditions should be ensured in order to produce a safe quality product. However, although some hazards associated with primary production of milk represent potential risks to consumers, fortunately, they can be controlled following certain regulations. These hazards can be classified as physical (foreign bodies), chemical (pesticides, antibiotics, mycotoxins, heavy metals or disinfectants), and microbiological (pathogens). Complementarily, the dairy industry demands products from farms meeting desirable quality standards, which is achieved with the implementation of specific national and international standards aimed to reduce risks to an acceptable

Autor de correspondencia:

Apdo.postal: 304-3000 Heredia. Teléfono: (506) 25624565. leana.zumbado.gutierrez@una.cr 
minimum. These standards include those issued by the Codex Alimentarius Commission and the Food and Agriculture Organization (FAO). Therefore, dairy farmers, as well as associations, cooperatives, the industry and the government must promote and monitor the implementation of management measures that help to control the aspects that influence extraction and maintenance of milk.

Keywords: milk, primary production, food safety, dairy products, hazards

\section{Introducción}

Debido a su aporte nutrimental, la leche es uno de los alimentos de mayor importancia en el mundo. Además, es producida para funcionar, exclusivamente, como fuente de alimento; por esto, un factor fundamental, que influye sobre el valor de aceptación y comercialización de la leche, es la calidad que presenta (Reyes et al. 2011; FAO 2015). En Costa Rica, por ejemplo, el consumo, per cápita, de productos lácteos fue de 199 kg para el 2012 (Cámara Nacional de Productores de Leche 2013).

La producción primaria de la leche reviste especial importancia en la cadena de producción de lácteos, por lo cual, debe asegurarse que sea producida a partir de animales sanos, bajo condiciones de manejo aceptables y en equilibrio con el ambiente. Las demandas, cada vez más estrictas del consumidor, recalcan la necesidad de disponer de alimentos inocuos y de calidad, así como en la importancia de conservar la sanidad de la leche para mantener la salud pública. Esto ha llevado a los investigadores y productores de leche a trabajar en el desarrollo de programas para mejorar su calidad y sanidad (Reyes et al. 2011; FAO \& FIL 2012; FAO 2015).

Si bien es cierto, la pasteurización de la leche, distribuida comercialmente, ha reducido, en gran medida, el riesgo de infección resultante del consumo de leche contaminada, aún una parte de la población sigue consumiendo leche cruda y productos hechos a partir de ella; por ejemplo: quesos frescos, natillas, cuajada, entre otros, con riesgo de sufrir alguna enfermedad. De acuerdo con estudios, los consumidores más frecuentes de la leche cruda son las familias de productores de leche, así como los empleados de las lecherías (Jayarao et al. 2006). Asimismo, es frecuente observar la venta de leche y algunos derivados crudos a domicilio, especialmente en zonas rurales, lo cual extiende el peligro de enfermedad a otros sectores de la población.

Es importante resaltar que los ganaderos están implicados en la producción de alimentos destinados al consumo humano, por ello deben asegurar la calidad nutricional e inocuidad de los productos que se originan en sus fincas. De ese modo, las buenas prácticas, en la explotación, son la base de una producción de leche que cumpla con las expectativas más altas de la industria alimentaria y de los consumidores (FAO \& FIL 2012; Flores-Miyamoto 2014).

Más de 200 enfermedades, causadas por una variedad de agentes como: bacterias, hongos, virus, y parásitos, pueden transmitirse a través de alimentos. De acuerdo con los Centros para la Prevención y el Control de Enfermedades (CDC por sus siglas en inglés), cada año, millones de enfermedades, en los Estados Unidos, pueden ser rastreadas hasta patógenos transmitidos por los alimentos (Oliver et al. 2005). 
Los consumidores exigen leche segura, libre decontaminación y sin características organolépticas indeseables; de ese modo, un ambiente limpio, en las áreas de producción primaria, vacas saludables, así como el cumplimiento de las buenas prácticas agrícolas, serán necesarias para cumplir tal exigencia del consumidor. Al mismo tiempo, esa exigencia se traslada a la industria lechera que, por ende, demanda un producto que cumpla con estándares de calidad e inocuidad; esto se logra con la aplicación de protocolos específicos de ordeño bien estructurados, máquinas de ordeño efectivas y buena higiene en general (Reyes et al. 2011).

La leche es un producto muy perecedero, debe conservarse a bajas temperaturas y ser distribuida o transformada rápidamente, especialmente debido a los peligros que la pueden afectar, tales como contaminación y multiplicación de microorganismos saprófitos; contaminación con bacterias patógenas; alteración físico-química de sus componentes; absorción de olores extraños; generación de malos sabores y contaminación con sustancias químicas, tales como: pesticidas, antibióticos, metales, detergentes, desinfectantes, etc. Estos tipos de contaminación, ya sea en forma aislada o en conjunto, afectan, en forma negativa, la calidad higiénica y nutricional del producto $y$, consecuentemente, se vuelven un peligro para la salud pública y la economía de cualquier país (Reyes et al. 2011; ICMSF 2012).

El riesgo de sufrir enfermedad de transmisión alimentaria (ETA) se ha incrementado notablemente durante los últimos 30 años. Actualmente, casi un cuarto de la población está en mayor riesgo de padecer enfermedad por esta causa. Consecuentemente, la prevención de enfermedades, y la muerte asociada con patógenos transmitidos por los alimentos, sigue siendo un importante problema de salud pública. Por otra parte, la seguridad de los alimentos es un problema mundial. Un aumento en la importación y exportación de productos alimenticios podrían conducir a la introducción y establecimiento de nuevas enfermedades en áreas geográficas que nunca han experimentado ciertos agentes patógenos transmitidos por alimentos (Muñoz 2004; Oliver et al. 2005).

En este contexto, el objetivo de este trabajo consiste en describir los conceptos relacionados con la inocuidad de la leche, e impulsar la aplicación de medidas de manejo que promuevan el control de los procesos, o aspectos, que se aplican durante la extracción y mantenimiento de la leche en la finca.

\section{Peligros microbiológicos en lácteos}

Las enfermedades causadas por patógenos, asociados a alimentos, mejor conocidas como Enfermedades Transmitidas por Alimentos (ETA), constituyen un problema de salud pública mundial (OMS 2015). Estos eventos han sido, ampliamente, influenciados por la globalización, la expansión demográfica, la industrialización, la distribución, el comercio, la centralización de la producción y suministro de los alimentos, así como la evolución y adaptación microbiana. Las ETA son comúnmente agudas; pero, también, pueden ser crónicas, con secuelas a largo plazo; (IMCSF 2002) los síntomas de las ETA van desde gastroenteritis leve a severa, llegando, inclusive, a enfermedad incompatible con la vida. 
La leche de origen bovino, y sus productos derivados, puede albergar una variedad de microorganismos, convirtiéndose en importantes fuentes de patógenos causantes de ETA. La presencia de este tipo de patógenos, en la leche, puede ser debido al contacto directo con fuentes contaminadas en el entorno de la finca, o de la excreción directa de la ubre de un animal infectado.

Aun cuando sea posteriormente pasteurizada, la industria láctea debe preocuparse por la calidad microbiológica de la leche del tanque, debido a que: 1) algunos brotes de enfermedades, en personas, han sido relacionados con el consumo de leche sin pasteurizar; así como, también, se han rastreado hasta leche pasteurizada; 2) la leche sin pasteurizar se consume, en algunos casos, directamente por los productores de leche, empleados agrícolas y sus familias, vecinos y defensores de leche cruda; 3 ) la leche no pasteurizada se consume, directamente, por un gran segmento de la población, a través del consumo de varios tipos de quesos u otros subproductos, fabricados con leche no pasteurizada; 4) la entrada de agentes patógenos, transmitidos por los alimentos, a través de leche cruda contaminada, en plantas de procesamiento de alimentos lácteos, pueden llevar a la persistencia de estos patógenos en las biopelículas, con la posterior contaminación de productos lácteos procesados y la consecuente exposición de los consumidores a bacterias patógenas; 5) la pasteurización inadecuada, o defectuosa, no va a destruir todos los patógenos presentes en la leche (Oliver et al. 2005; Jayarao et al. 2006; Oliver et al. 2009). Asimismo, agentes patógenos, como Listeria monocytogenes, pueden sobrevivir y prosperar en los procesos post-pasteurización, lo que conduce a una nueva contaminación de los productos lácteos. Estas vías suponen un riesgo para los consumidores mediante la exposición directa a los patógenos presentes en los productos lácteos sin pasteurizar, o recontaminados, posterior a la pasteurización (Oliver et al. 2005).

Según Oliver et al. (2005), la prevalencia de patógenos, transmitidos por los alimentos en leche, está influenciada por numerosos factores tales como: tamaño de la explotación, el número de animales de la finca, la higiene, prácticas de gestión agrícola, variación en el muestreo y tipos de muestras evaluadas, las diferencias en la especificidad y sensibilidad de las metodologías utilizadas, ubicación geográfica y la temporada. Sin embargo, a pesar de las posibles variaciones, la leche puede ser una fuente importante de patógenos, transmitidos por los alimentos, que afectarían la salud humana.

\section{Bacterias}

En países industrializados, las causas más frecuentes, asociadas a ETA, son: Salmonella spp., Staphylococcus aureus, Clostridium perfringens y Vibrio parahaemolyticus; además, Campylobacter spp. termofílico está tomando mayor importancia. Antes de la década de 1990, en muchos países, la mayor parte de brotes, asociados a alimentos, fueron causados por Salmonella spp., S. aureus y C. perfringens. Se debe hacer notar que Campylobacter jejuni/coli, Escherichia coli 0157:H7 y Listeria monocytogenes no fueron reconocidas como patógenos hasta las últimas décadas (IMCSF 2002; Oliver et al. 2005; Jayarao et al. 2006; Oliver et al. 2009). 
Dentro de ese ámbito, bacterias del género Salmonella han sido consideradas, tradicionalmente, el mayor patógeno causante de ETA a nivel mundial. Algunos alimentos implicados en brotes causados por este agente incluyen: carne de res, cerdo y aves, huevos y subproductos, vegetales, especias así como la leche y sus subproductos (ICMSF 2002). Inclusive, en la República Popular China, se ha reportado la presencia de Salmonella spp. en fórmulas en polvo con base láctea para niños (Yang et al. 2014).

En años recientes, en países desarrollados, la incidencia de enfermedad causada por Campylobacter spp. termofílico ha excedido debido a Salmonella spp. No obstante, los brotes de campilobacteriosis son raros. La mayoría de casos son esporádicos y, comúnmente atribuidos al consumo de aves pobremente cocidas o por contaminación cruzada con aves crudas (ICMSF 2002); sin embargo, otros alimentos asociados son: el agua sin tratamiento y la leche cruda (Oliver et al. 2005; Oliver et al. 2009).

Por otra parte, la enfermedad causada por L. monocytogenes no es frecuente, a pesar de esto, puede llegar a ser muy severa, con alta letalidad en la población en mayor riesgo, tal como: infantes, mujeres embarazadas y personas inmunocomprometidas. Esta bacteria es ubicua; los brotes causados por ella se asocian a alimentos como: productos hechos a base de leche cruda, helados, mantequilla, alimentos listos para consumo, surimi, mejillones, trucha y vegetales (ICMSF 2002).

En cuanto al transporte de patógenos, las fuentes alternativas de leche o productos lácteos; por ejemplo, leche de cabra o de oveja, presentan riesgos similares a los de la leche de la especie bovina (Oliver et al. 2009). En un estudio publicado por Abou-Eleinin et al. (2000), se aisló $L$. monocytogenes de $17 \%(n=450)$ de las muestras de leche de cabra a granel que se probaron.

Por otra parte, se ha establecido que, aun habiendo diferencias en la gestión del hato lechero, comparando lecherías convencionales versus orgánicas, la calidad e inocuidad de la leche es notablemente similar entre las fincas (Mullen et al. 2014). En ese estudio, se observó una diferencia no significativa, en la proporción de muestras de leche por vaca, sin crecimiento microbiológico, entre fincas convencionales y fincas orgánicas. Además, no se observó diferencias significativas para la prevalencia de Staphylococcus aureus, Staphylococcus spp coagulasa negativo. Streptococcus spp., o Corynebacterium spp. en las muestras de leche por vaca. Paralelamente, Cicconi-Hogan et al. (2014) tampoco evidenciaron diferencias significativas de prevalencia de Staphylococcus spp., resistentes a la meticilina, entre lecherías convencionales y orgánicas.

Además, algunas cepas de bacterias formadoras de esporas (por ejemplo, Bacillus spp. y Paenibacillus spp.) pueden sobrevivir la pasteurización y crecer posteriormente a temperaturas de refrigeración, causando descomposición de la leche fluida pasteurizada. Por ejemplo, Bacillus cereus es una bacteria causante de intoxicaciones alimentarias, que provoca vómito y diarrea en pocas horas (Masiello et al. 2014).

Otros patógenos bacterianos, vinculados con la leche, incluyen, Streptococcus pyogenes, Mycobacterium tuberculosis, Mycobacterium avium ssp. paratuberculosis (MAP), Brucella 
abortus (IMCSF 2002; Stabel et al. 2014) y Arcobacter spp. (Serraino \& Giacometti 2014). Al respecto, Stabel et al. (2014) demostraron que la excreción de MAP a la leche se ve afectada por el estado de infección de la vaca (subclínica o clínica), así como la fase de la lactancia. Adicionalmente, Cronobacter sakazakii (antes llamado Enterobacter sakazakii) es causante de ETA, principalmente en niños menores de 6 meses, cuya principal vía de transmisión son las fórmulas lácteas infantiles (Petrola et al. 2013).

\section{Protozoarios}

Se ha propuesto que el riesgo de adquirir una infección con Toxoplasma gondii, por el consumo de leche de vaca, es mínimo, pero no se puede excluir que cualquier tipo de leche es una fuente potencial de infección si se consume cruda (Cenci-Goga et al. 2011). Esta enfermedad es, principalmente, asociada con el consumo de leche de cabra no pasteurizada. Los padecimientos ocasionados por este protozoario son mucho más serios en personas inmunocomprometidas y en mujeres embarazadas. Casos esporádicos de infecciones por $T$. gondii han sido asociados a carne mal cocida o productos de la pesca (ICMSF 2002).

\section{Virus}

Aunque no se han registrado virus transmitidos directamente por el consumo de leche contaminada, Case et al. (2015) mencionan la asociación significativa entre el virus de la Leucemia Enzoótica Bovina (LEB) con la incidencia de cáncer del tejido mamario en humanos. En este estudio de casos y controles, se investigó específicamente la presencia de ADN de LEB en tejido mamario de pacientes con diagnóstico de cáncer de mama versus los controles, encontrándose un riesgo atribuible de 37\%, con un Odds Ratio de 3,07 (IC 1.66-5.69, $p=0.0004$ ) (Case et al. 2015).

\section{Hongos toxigénicos}

Las micotoxinas son metabolitos tóxicos producidos por hongos comunes cuando éstos crecen en condiciones propicias de temperatura, humedad y nutrientes. Las más reconocidas, que juegan un rol importante en enfermedades de las personas, son las aflatoxinas, producidas por Aspergillus flavus y Aspergillus parasiticus que crecen en maní y maíz. Estas causan, primariamente, cáncer hepático y son responsables de muchas muertes anualmente, especialmente en países en desarrollo (IMCSF 2002).

La aflatoxina M1 (AFM1) es el metabolito hidroxilado de aflatoxina B1 (AFB1), se puede encontrar en la leche $\mathrm{y}$, posteriormente, en otros productos lácteos cuando los animales lactantes son criados con alimentos concentrados contaminados (Prandini et al. 2009).

Las fuentes de la contaminación por aflatoxinas en los suplementos concentrados para animales pueden variar geográficamente, aunque la contaminación de cultivos con estos productos tóxicos es un problema mundial no limitado a países en desarrollo, siempre y 
cuando las condiciones climáticas y tecnológicas favorezcan su producción (Prandini et al. 2009).

Existen resultados ambiguos sobre el efecto que, cambios físicos, (calentamiento, enfriamiento o congelación) tienen sobre la concentración de la micotoxina en la leche (Prandini et al. 2009). Los resultados de la evaluación, mediante un modelo de exposición, sugieren que la presencia de micotoxinas, en niveles de contaminación normales en la alimentación bovina, no debe dar lugar a importantes concentraciones de micotoxinas en la leche (Coffey et al. 2009). Sin embargo, Er et al. (2014) detectaron restos de aflatoxina M1 en leches y fórmulas comerciales para niños, en la ciudad de Ankara, Turquía, debido a que estas micotoxinas no se inactivan con la temperatura de pasteurización y desecación.

A su vez, se ha sugerido, mediante un análisis de sensibilidad, que la clave para reducir la contaminación por micotoxinas es tomar acciones sobre el terreno antes de la cosecha de granos para la producción de piensos (Coffey et al. 2009).

Otras micotoxinas, implicadas como causantes de enfermedad, son las fumonisinas, producidas por Fusarium verticilloides y $F$. proliferatum, han sido implicadas en cáncer esofágico en humanos, generalmente presentes en diversidad de granos y otros productos. También, han sido detectadas en leche, especialmente FB1 (Gazzotti et al. 2009).

Los tricotecenos, producidos por Fusarium graminearum y otras especies relacionadas, en cereales, son causa de inmunosupresión y consecuentemente tienen un papel importante en la disminución de la resistencia a enfermedades. Existe evidencia de que las aflatoxinas son también inmunosupresoras. Estos componentes están ampliamente distribuidos en alimentos de algunos países y pueden tener un rol importante, pero insospechado, en ampliar la susceptibilidad a una gran variedad de enfermedades (IMCSF 2002).

Coffey et al. (2009) propusieron, utilizando un modelo de simulación, que las concentraciones de micotoxinas en leche, como aflatoxina M1, ocratoxina, fumonisina B1 y zearalenona, no serían suficientemente altas en leche, como para sobrepasar el máximo de la ingesta diaria admisible (IDA) según las guías de la Unión Europea (UE). Sin embargo, se determinó, en este estudio, que aflatoxina M1, tenía el potencial para exceder los límites establecidos por la UE. (Coffey et al., 2009).

\section{Peligros químicos en lácteos}

Como se ha dicho, la leche y sus derivados pertenecen al grupo de alimentos de mayor riesgo en salud pública, no sólo por tratarse de un alimento básico, por tanto de alto consumo, sino por su susceptibilidad de transmitir enfermedades debido a la presencia de microorganismos, a lo cual se debe sumar la presencia de contaminantes como: medicamentos veterinarios, hormonas, plaguicidas y antibióticos (Máttar et al. 2009). En este sentido, se ha demostrado que, después de la administración de cualquier tratamiento veterinario, los residuos del medicamento aparecen en los productos comestibles obtenidos de los animales tratados (Noa-Lima et al. 2009). 
La calidad de un producto, cualquiera que sea su naturaleza, está dada por disposiciones legales en sanidad y composición, así como por la aceptación del consumidor. La evidencia, que refleja la amplia investigación en inocuidad alimentaria, ha desencadenado la necesidad de crear normas que regulen el uso de los medicamentos veterinarios. A nivel internacional, el Codex Alimentarius, a través de la Comisión de Expertos en Aditivos Alimentarios (JECFA, por sus siglas en inglés), se encarga de recomendar los límites máximos permitidos para los múltiples residuos que puedan resultar tóxicos para el hombre. Los límites máximos permitidos se refieren a la máxima concentración de una sustancia que se acepta en un alimento determinado. Costa Rica está suscrito a una serie de convenios internacionales que lo obligan a establecer los mecanismos necesarios para asegurar que las normas se cumplan (Luna 2004).

Para el caso de la leche, la normatividad costarricense vigente, de acuerdo con el Reglamento Técnico: RTCR: 401-2006: Leche cruda y Leche Higienizada, referida a leche de vaca, ya sea cruda o pasteurizada, establece que esta debe respetar los límites máximos establecidos, según la clasificación de los inhibidores microbianos (Gobierno de la República de Costa Rica 2007). Además, este reglamento instaura la prohibición de la comercialización de leche para consumo humano directo, si sobrepasa los límites establecidos; sin embargo, no establece posibles destinos o normas para un correcto descarte de la leche contaminada.

Los residuos o inhibidores en leche se han definido como: toda sustancia química o biológica que, al ser administrada o consumida por el animal, se elimina o permanece como metabolito en la leche, en la carne o en los huevos, con efectos nocivos para el consumidor (FAO 2012). Los medicamentos veterinarios más usados, en la práctica veterinaria, incluyen los promotores de crecimiento y antimicrobianos. Entre estas sustancias se encuentran los antibióticos empleados en el tratamiento de enfermedades infecciosas, los desinfectantes y detergentes en los procesos de limpieza y desinfección; los pesticidas en el control de garrapatas, moscas y malezas (Máttar et al. 2009). Específicamente, al hablar del uso de antibióticos, los animales son tratados con tres propósitos básicos: profilaxis, tratamiento terapéutico y promoción del crecimiento; de ese modo, se utiliza, ampliamente, en los tratamientos de la mastitis y otras enfermedades infecciosas como neumonía y pododematitis, entre otros. Actualmente, son muy utilizados, en el tratamiento profiláctico de las vacas no lactantes (vaca seca) y, en este caso, pueden ser excretados residuos en niveles elevados durante importantes períodos después del parto (Máttar et al. 2009).

Estosresiduosdeantimicrobianosenlosalimentos, especialmenteantibióticos, producennumerosos problemas en el humano, siendo el de mayor importancia la aparición de multiresistencia en bacterias patógenas producto de haber sido sometidas a bajas concentraciones sub- terapéuticas, lo cual representa un peligro potencial para la salud del consumidor; además, representa un importante problema para la industria láctea, pues los cultivos iniciadores, empleados en la producción de derivados lácteos fermentados, tales como queso y yogurt, son extremadamente sensibles a bajas concentraciones de antibióticos en la leche (Noa-Lima et al. 2009).

Entre los efectos adversos, que la presencia de antibióticos en leche puede provocar en los humanos, se pueden citar: alergias, disbacteriosis, sobrecrecimientos, resistencias y 
algunos efectos tóxicos. Además, los antibióticos, presentes en la leche, pueden inducir alteración de la flora intestinal, desarrollo de microorganismos patógenos y reducción de la síntesis de vitaminas esenciales (Luna 2004; Máttar et al. 2009).

\section{Patógenos en el ambiente de las fincas lecheras}

Las fincas lecheras son importantes reservorios de patógenos causantes de ETA, los cuales llegan a la leche por dos vías principales: el contacto directo con fuentes contaminadas en ambiente de la finca o por la excreción directamente de la ubre de un animal infectado (Figura 1). Así, se ha documentado que la fuente primaria de los patógenos asociados a ETA, en la leche, parece estar directamente vinculada a la contaminación fecal que se produce durante el proceso de ordeño (Oliver et al. 2005). Esto es consecuencia de que la mayoría de los patógenos, transmitidos por los alimentos, habitan en el tracto intestinal de los rumiantes; específicamente, el ganado lechero se considera uno de las principales reservorios de Salmonella spp., Campylobacter spp., y Shiga toxina E. coli (STEC). Otra bacteria de relevancia es la Listeria spp., la cual está muy extendida en la naturaleza y vive de forma natural en las plantas y los suelos.

Diversos estudios epidemiológicos han demostrado que el ganado, probablemente, se infecta a través del consumo de agua y alimentos contaminados con heces y otras secreciones o excreciones del ganado (Oliver et al. 2005). Así, por ejemplo, Medhanie et al. (2014) demostraron presencia de Salmonella spp., Campylobacter spp. y E. coli 0157:H7 en muestras de heces de aves, las cuales fueron recolectadas en los comederos de los animales de las lecherías estudiadas.

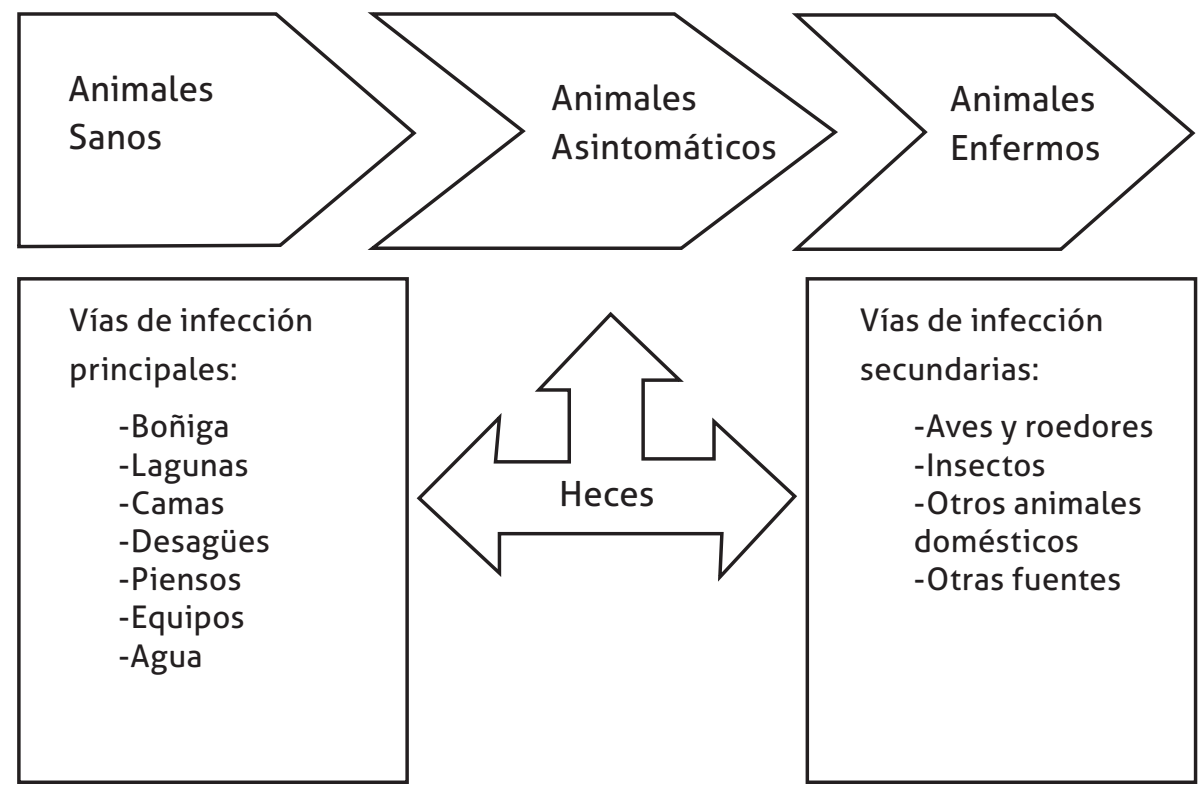

Figura 1. Ciclo de los patógenos causantes de ETA en fincas lecheras. Modificado de Oliver et al. (2005) 
La presencia de agentes patógenos en la leche del tanque parece estar directamente relacionada con la contaminación fecal que se produce, principalmente, durante la cosecha de leche cruda; sin embargo, algunos patógenos causantes de ETA (P. ej. S. aureus) pueden causar mastitis, en cuyo caso, el microorganismo puede ser excretado directamente en la leche (Oliver et al. 2005). Al respecto, Borneman \& Ingham (2014) encontraron una fuerte evidencia de correlación entre el recuento total aerobio (RTA) y conteo de células somáticas (CCS) en muestras de leche. Sin embargo, también reportan que los resultados de las pruebas de RTA están, probablemente, influenciados por varias otras prácticas de manejo, además de la influencia de CCS. A este respecto, Lee et al. (2014) evidenciaron la presencia de $S$. aureus en superficies del equipo de ordeño, utensilios y manipuladores de la leche.

La posible participación de $S$. aureus en los casos de mastitis subclínica y su ocurrencia en la leche para el consumo humano, y su reconocida capacidad para formar biopelículas (Oliver et al. 2005), destacan la necesidad de mejorar las prácticas de higiene para prevenir la contaminación de la leche, por esta vía, directamente en las lecherías (Lee et al. 2014). Las buenas prácticas en la finca, así como los procesos de desinfección de los equipos y del personal, durante el ordeño, reducirán la posibilidad de introducción de la leche cruda contaminada con patógenos en plantas de procesamiento, y su persistencia en biopelículas, que representa un importante riesgo de contaminación, aún después de la pasteurización y que, a su vez, podría dar lugar a la exposición de los consumidores a bacterias patógenas (Oliver et al. 2005).

Los análisis microbiológicos pueden ser una herramienta útil en el manejo de la inocuidad alimentaria desde la finca; sin embargo, estos análisis deben ser seleccionados y aplicados con conocimiento de sus limitaciones, así como sus beneficios y los propósitos para los que deben ser usados. En muchas circunstancias, otras formas de evaluación son más rápidas e igualmente efectivas. La necesidad de analizar microbiológicamente varía a lo largo de la cadena; de ese modo, los puntos de análisis deben ser seleccionados en la cadena de producción en la finca, donde la información del estatus microbiológico pruebe ser más provechosa para los propósitos de control (ICMSF 2002).

\section{El concepto del sistema de manejo de la sanidad alimentaria}

Los respectivos roles de la industria y el gobierno deben estar claros dado que, es a través de sus actividades colectivas, que los sistemas de inocuidad se desarrollan y verifican de manera efectiva (ICMSF 2002). Los inspectores de inocuidad utilizan evidencia epidemiológica para ligar las enfermedades en humanos con un agente microbiológico y, si es posible, con un alimento. En caso de encontrarse evidencia, debe establecerse una nueva política para prevenir o reducir futuros eventos de tal naturaleza, así como para prevenir el deterioro de la salud pública. En esos casos, para entender mejor las opciones disponibles para el control, se requiere información adicional (ICMSF 2002).

Se debe determinar la posibilidad de prevención mediante la utilización de información de estudios epidemiológicos, el conocimiento del peligro, y las condiciones que llevan al padecimiento de una enfermedad mediada por alimentos. Los inspectores de inocuidad y los 
analistas de riesgo del ente oficial, deben determinar un objetivo de inocuidad de alimentos (OIA) para prevenir la ocurrencia de un peligro en un tipo de alimento, por ejemplo: la frecuencia/ concentración máxima tolerable de un peligro microbiológico en leche (ICMSF 2002).

Si se estima que el OIA es alcanzable, el paso siguiente es establecer un criterio, que se pueda utilizar, para evaluar si las medidas establecidas controlarán efectivamente el peligro y alcanzarán el objetivo planteado. Los siguientes ejemplos son criterios en pasteurización de la leche: criterios de desempeño (recuento de bacterias en producto antes y después del proceso de pasteurización), criterio de proceso $\left(71^{\circ} \mathrm{C}\right.$ durante 15 segundos) y/o criterio del producto ( $\mathrm{pH}$, agua disponible). Los criterios se alcanzan a través de las Buenas Prácticas Higiénicas (BPH) y Análisis de Peligros y Puntos Críticos de Control (HACCP por sus siglas en inglés), incluyendo procedimientos de monitoreo, para asegurar el control, al tomar en cuenta la variabilidad de los procesos (ICMSF 2002).

La seguridad microbiológica de los alimentos es, principalmente, garantizada mediante la adecuada selección de la materia prima; el control de las diversas fuentes de contaminación; el diseño del producto y el control de los procesos; así como por la aplicación de las BPH y el HACCP durante la producción, procesado, distribución, almacenamiento, venta, preparación y uso (Cuadro 1). Estos sistemas preventivos, de tipo comprensivo, ofrecen mucho más control que solo realizar análisis al producto final.

Cuadro 1. Medidas que han resultado exitosas para controlar los peligros asociados con alimentos. Modificado de IMCSF (2002)

\begin{tabular}{|c|c|c|c|}
\hline Agente & Peligro & Medidas de control & Otras Medidas \\
\hline \multirow[t]{10}{*}{ Bacteria } & Bacilus cereus & $\begin{array}{l}\text { Control del tiempo/temperatura durante la cocción, en- } \\
\text { friamiento y almacenamiento }\end{array}$ & $\mathrm{BPH}$ \\
\hline & Brucella spp. & Erradicación del agente & Salud Animal \\
\hline & & Pasteurización & \\
\hline & Campylobacter spp. & $\begin{array}{l}\text { Selección de materias primas, evitar contaminación cru- } \\
\text { zada }\end{array}$ & $\mathrm{BPH}$ \\
\hline & Clostridium botulinum & Control tiempo/temperatura, $\mathrm{pH}$ y Aw de productos & HACCP \\
\hline & E. coli & $\begin{array}{l}\text { Cocción, fermentación y añejamiento controlado y evitar } \\
\text { contaminación cruzada }\end{array}$ & $\mathrm{BPH}$ \\
\hline & Listeria monocytogenes & $\begin{array}{l}\text { Cocción, fermentación y añejamiento controlado y evitar } \\
\text { contaminación cruzada }\end{array}$ & $\mathrm{BPH}$ \\
\hline & Mycobacterium bovis & Erradicación de TB en hato, pasteurización de la leche & $\mathrm{BPH}$ \\
\hline & Salmonella spp. & $\begin{array}{l}\text { Cocción, fermentación y añejamiento controlado y evitar } \\
\text { contaminación cruzada }\end{array}$ & $\mathrm{BPH}$ \\
\hline & Staphylococcus aureus & $\begin{array}{l}\text { Cocción, fermentación y añejamiento controlado y evitar } \\
\text { contaminación cruzada }\end{array}$ & $\mathrm{BPH}$ \\
\hline Parásitos & Tокорlasma gondii & $\begin{array}{l}\text { Pasteurización de lácteos, congelamiento y cocción de } \\
\text { carnes, lavado profundo en vegetales }\end{array}$ & $\mathrm{BPH}$ \\
\hline
\end{tabular}

BPH: Buenas prácticas higiénicas; HACCP: Análisis de Peligros y Puntos Críticos de Control; Aw: actividad acuosa o agua disponible. 
Los análisis microbiológicos requieren mucho tiempoy, comúnmente, carecen de sensibilidad y especificidad; además, los niveles de muestreo aplicados, rutinariamente, tienen poca probabilidad de detectar lotes defectuosos, especialmente cuando la proporción de unidades defectuosas o contaminadas es baja dentro del lote (ICMSF 2002). Al reconocer las limitaciones de analizar el producto final, para asegurar la seguridad microbiológica del producto, se ha recomendado un sistema de verificación basado en el uso de BPH y Buenas Prácticas Pecuarias (BPP), en combinación con el sistema HACCP, como un medio más confiable de asegurar la inocuidad del producto en la industria actual de alimentos (FAO \& FIL 2012; ICMSF 2002; SENASA 2012).

\section{Buenas Prácticas Pecuarias (BPP) para la producción de leche}

Con el objetivo de preservar los productos de consumo humano y animal de contaminantes y otras condiciones, que pueden provocar daños a los consumidores, se crearon las guías de Buenas Prácticas para las industrias reguladas. Precisamente, a partir de los cambios en los hábitos alimenticios, el incremento de poblaciones más vulnerables, los avances técnicos y científicos, la globalización en el comercio, el aumento de la difusión del conocimiento, y la acumulación de grandes producciones en plantas multifuncionales, se ha generado una fuerte exigencia por la inocuidad de los alimentos, concebida en todos los eslabones de las cadenas productivas con un sentido de prevención y garantía (Villoch 2010; FAO \& FIL 2012).

Las lecherías se encuentran en uno de los primeros escalones de la cadena agroalimentaria láctea y, por tanto, están sujetas a la necesidad de organizar su producción de conformidad con estas demandas de garantía de la inocuidad (Villoch 2010). En la consecución de este propósito, las guías de BPP pueden ser de mucha utilidad para alcanzar la eficiencia en la obtención de leche de óptima calidad nutricional e inocua.

Los documentos de BPP son guías o manuales que enumeran recomendaciones orientadoras sobre los requerimientos que deben garantizarse con la meta de cumplir con los requisitos de calidad y, fundamentalmente, los de inocuidad de los alimentos. Los contenidos de estos instrumentos se orientan a cumplir con los indicadores de calidad e inocuidad; sin embargo, se incluyen algunas exigencias relacionadas con bienestar animal, gestión socioeconómica y el ambiente (Figura 2) (Villoch 2010; FAO \& FIL 2012).

El Codex Alimentarius ha creado los códigos de higiene para la industria de alimentos desde 1963. Estos documentos recomiendan las prácticas más adecuadas para asegurar la limpieza y minimizar las contaminaciones en estos productos a lo largo de las distintas fases agroindustriales (FAO \& OMS 2006). Se plantea que los códigos de higiene cumplen, parcialmente, con la misión recomendada en las Buenas Prácticas y solo es un prerrequisito para los sistemas de inocuidad, basados en el sistema HACCP. El marco internacional, para garantizar que la leche y los productos lácteos son saludables e idóneos, está contenido en el Código Internacional de Prácticas Recomendado - Principios Generales de Higiene de los Alimentos (CAC/RCP 1-1969, Rev. 4) (2003), junto con el Código de Prácticas de Higiene para la Leche y los Productos Lácteos del Codex (CAC/RCP 57-2004) (2004). 


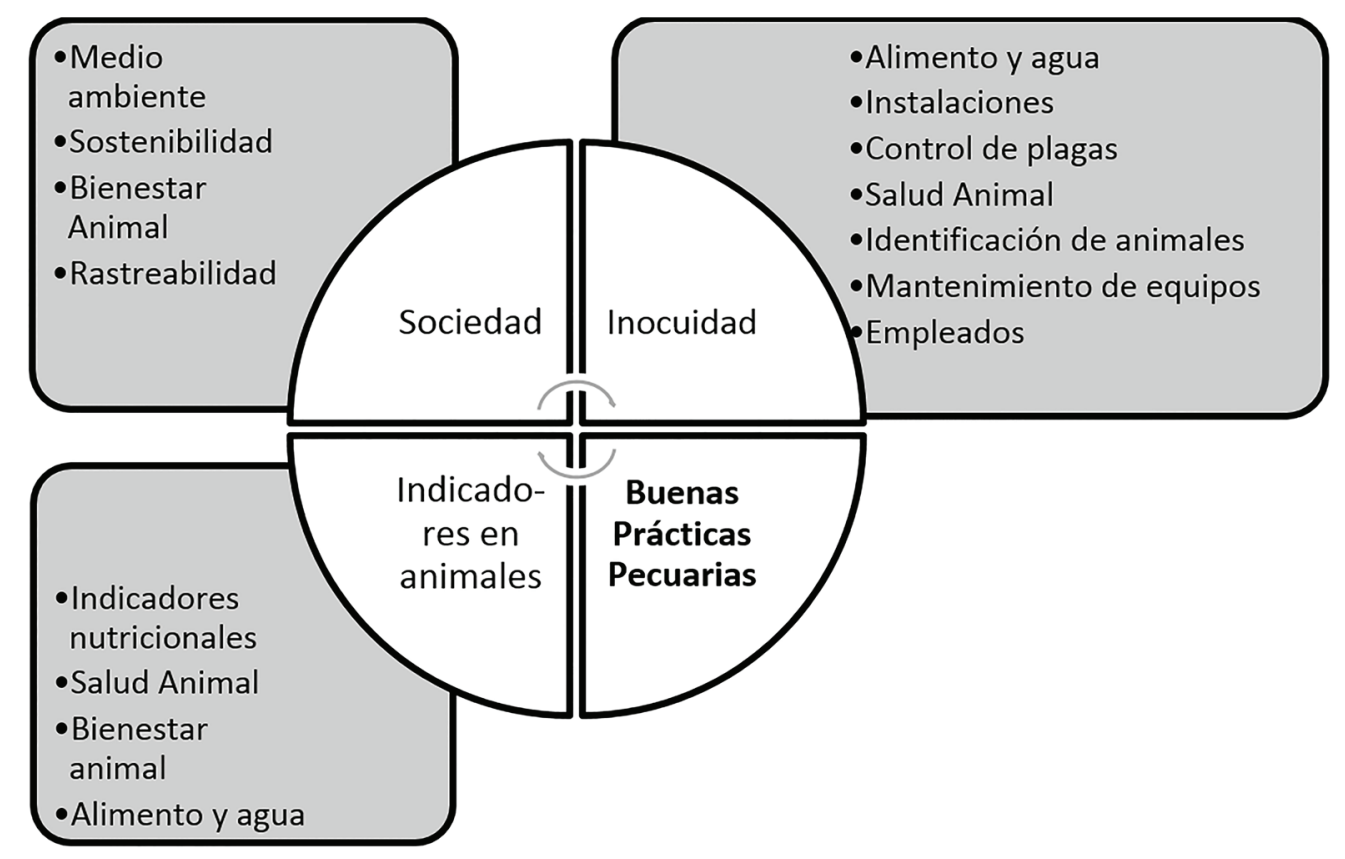

Figura 2. Aspectos contemplados en los requerimientos de un Manual de Buenas Prácticas Pecuarias (creación propia a partir de Villoch, 2010).

Estos códigos están orientados a asegurar la inocuidad de los alimentos, con requerimientos dirigidos a operaciones de saneamiento o higiene $y$, por tanto, no contempla aspectos como el bienestar animal, o la protección de los trabajadores. Para la producción de leche, se debe conocer lo recomendado en el código elaborado, específicamente, para este producto: Código de Prácticas de Higiene para la Leche y los Productos Lácteos, que data del 2004 pero, además, debe cumplirse con los requisitos planteados en el código General de Prácticas de Higiene, diseñado para cualquier alimento (Código Internacional de Practicas Recomendado-Principios Generales de Higiene de los Alimentos 2003) y, también, en el Código de Prácticas de Higiene para la transportación de alimentos a granel (2001).

\section{Conclusiones}

La leche, por sus características, como altamente rica en nutrientes y con una elevada actividad acuosa (Aw por sus siglas en inglés), es un caldo de cultivo perfecto para el crecimiento de bacterias, las cuales podrían provocar condiciones sensoriales indeseables o, en caso extremo, enfermedades en los consumidores, amenazando la salud pública.

Los productores de leche, así como las asociaciones, cooperativas, industria y gobierno, deben impulsar y verificar la aplicación de medidas de manejo que colaboren a controlar los procesos o aspectos que se aplican durante la extracción y mantenimiento de la leche. 
Cada lechería podría iniciar con la implementación de las recomendaciones emitidas por el Codex Alimentarius, por medio de las BPP y BPH, en combinación con el sistema HACCP, velando, también, por cumplir las normativas nacionales propias, al ajustarse a las recomendaciones de la realidad nacional y promoviendo la mejora continua.

\section{Referencias bibliográficas}

Abou-Eleinin, A.A., Ryser E.T. \& Donnelly C.W. 2000. Incidence and seasonal variation of Listeria species in bulk tank goat's milk. J Food Prot. 63: 1208-1213.

Borneman, D.L. \& Ingham, S. 2014. Correlation between standard plate count and somatic cell count milk quality results for Wisconsin dairy producers. J. Dairy Sci. 97: 26462652. doi:10.3168/jds.2013-7784.

Cámara Nacional de Productores de Leche. 2013. Consumo aparente y per cápita de productos lácteos. http://www.proleche.com/recursos/documentos/Consumo\%20 Aparente.pdf (Consulta: 14 Enero 2015).

Case, G., Hua M.S., Jensen, H.M., Jin, D.L., Hudes, M. \& Block, G. 2015. Exposure to Bovine Leukemia Virus is associated with breast cancer: a case- control study. PLoS ONE 10(9): e0134304. doi:10.1371/journal.pone.0134304.

Cenci-Goga, B.T., Rossitto P.V., Sechi, P., McCrindle, M.E. \& Cullor, J.S. 2011. Toxoplasma in animals, food, and humans: an old parasite of new concern. Foodborne Pathogens and Disease 8 (7): 751-762. doi: 10.1089/fpd.2010.0795.

Cicconi-Hogan, K.M., Belomestnykh, N., Gamroth, M., Ruegg, P.L., Tikofsky, L. \& Schukken, Y.H. 2014. Short communication: Prevalence of methicillin resistance in coagulase-negative staphylococci and Staphylococcus aureus isolated from bulk milk on organic and conventional dairy farms in the United States. J. Dairy Sci. 97: 2959-2964. doi: 10.3168/jds.2013-7523.

Coffey R., Cummins, E. \& Ward, S. 2009. Exposure assessment of mycotoxins in dairy milk. Food Control. 20: 239-249.

Comisión del Codex Alimentarius. Comité del Codex sobre Leche y Productos Lácteos Código de Prácticas de Higiene para la leche y los productos lácteos. 2004; CAC/RCP 57-2004.

Comisión del Codex alimentarius. Comité de Higiene de los alimentos. Códigos de Prácticas de Higiene para el transporte de alimentos a granel. 2001. CAC/RCP 47-2001.

Comisión del Codex alimentarius. Comité de Higiene de los alimentos. Código internacional de Prácticas recomendado. 2003; Principio Generales de Higiene de los alimentos. CAC/RCP 1 - 1969, Rev 4-2003.

Er, B., Demirhan, B. \& Yentür, G. 2014. Investigation of aflatoxin M1 levels in infant followon milks and infant formulas sold in the markets of Ankara, Turkey. J. Dairy Sci. 97: 3328-3331. doi:10.3168/jds.2013-7831.

FAO (Organización de las Naciones Unidas para la Alimentación y la Agricultura). 2015. 
Producción lechera. http://www.fao.org/agriculture/dairy-gateway/produccionlechera/es/\#.VLk4NdKUcsc (Consulta: 14 Enero 2015).

FAO (Organización de las Naciones Unidas para la Alimentación y la Agricultura) y Federación Internacional de la Leche (FIL). 2012. Guía de buenas prácticas en explotaciones lecheras. Directrices FAO: Producción y Sanidad Animal No. 8, Roma.

FAO (Organización de las Naciones Unidas para la Alimentación y la Agricultura) y OMS (Organización Mundial para la Salud). 2006. Qué es el Códex Alimentarius. $3^{\text {ra }}$ Edición. FAO, Roma.

Gazzotti, T., Lugoboni, B., Zironi, E., Barbarossa, A., Serraino, A. \& Pagliuca, G. 2009. Determination of fumonisin B1 in bovine milk by LC-MS/MS. Food Control. 20: 11711174. doi: 10.1016/j.foodcont.2009.02.009.

Flores-Miyamoto, A., Reij, M.W. \& Velthuis, A.G.J. 2014. Do farm audits improve milk quality? J. Dairy Sci. 97: 1-9. doi:10.3168/jds.2012-6228.

International Commission for the Microbiological Specifications of Foods (ICMSF). 2002. Microorganisms in foods 7: Microbiological Testing in Food Safety Management. Springer, New York.

Jayarao, B. M., Donaldson, S. C., Straley, B. A., Sawant, A. A., Hegde, N. V. \& Brown, J. L. 2006. A survey of foodborne pathogens in bulk tank milk and raw milk consumption among farm families in Pennsylvania. J. Dairy Sci. 89: 2451-2458. doi:10.3168/jds.S00220302(06)72318-9.

Lee, S.H.I., Mangolin, B.L.C., Gonçalves, J.L., Neeff, D.V., Silva, M.P., Cruz, A.G. \& Oliveira, C.A.F. 2014. Biofilm-producing ability of Staphylococcus aureus isolates from Brazilian dairy farms. J. Dairy Sci. 97: 1812-1816. doi: 10.3168/jds.2013-7387.

Luna, C. 2004. Manual sobre el manejo de los medicamentos veterinarios y la calidad higiénica integral de los lácteos: guía para los productores artesanales y las pequeñas empresas procesadoras de lácteos. Editorial EUNA, Heredia. p.

Masiello, S.N., Martin, H.N., Watters, R.D., Galton, D.M., Schukken, Y.H., Wiedmann, M. \& Boor, K.J. 2014. Identification of dairy farm management practices associated with the presence of psychrotolerant sporeformers in bulk tank milk. J. Dairy Sci. 97: 40834096. doi: 10.3168/jds.2014-7938.

Máttar, S., Calderón, A., Sotelo, D., Sierra, M. \& Tordecilla, G. 2009. Detección de antibióticos en leches: un problema de salud pública. Rev. salud pública 11 (4): 579-590.

Medhanie, G.A., Pearl, D.L., McEwen, S.A., Guerin, M.T., Jardine, C.M., Schrock, J. \& LeJeune, J.T. 2014. A longitudinal study of feed contamination by European starling excreta in Ohio dairy farms (2007-2008). J. Dairy Sci. 97: 5230-5238. doi: 10.3168/jds.2014-8045.

Mullen, K.A., Sparks, L.G., Lyman, R.L., Washburn, S.P. \& Anderson, K.L. 2014. Comparisons of milk quality on North Carolina organic and conventional dairies. J. Dairy Sci. 96 (10): 6753-6762. doi: 10.3168/jds.2012-6519. 
Muñoz, H.A. 2004. Consideraciones Sanitarias en el Comercio Internacional: Estudio Introductorio. Editorial Investigaciones Jurídicas S.A, San José.

Noa-Lima, E., Noa, M., González, D., Landeros, P. \& Reyes, W. 2009. Evaluación de la presencia de residuos de antibióticos y quimioterapéuticos en leche en Jalisco, México. Rev. Salud Anim 31(1): 29-33.

Oliver, S.P., Jayarao, B.M. \& Almeida, R.A. 2005. Foodborne pathogens in milk and the dairy farm environment: food safety and public health implications. Foodborne Pathogens and Disease 2(2): 115-29.

Oliver, S.P., Boor, K.J., Murphy, S.C. \& Murinda, S.E. 2009. Food Safety Hazards Associated with Consumption of Raw Milk. Foodborne Pathogens and Disease 6 (7): 793-806. doi: 10.1089/fpd.2009.0302.

Organización Mundial de la Salud (OMS). 2015. Enfermedades de transmisión alimentaria. http://www.who.int/topics/foodborne_diseases/es/ (Consulta: 14 Enero 2015).

Petrola, M., Martínez, A., Tomé, E. Luigi, T. \& Rojas, T. 2013. Efecto de la temperatura de refrigeración y calentamiento de fórmulas lácteas infantiles en el crecimiento de Cronobacter sakazakii. An Venez Nutr 26 (2): 106-111.

Prandini, A., Tansini, G., Sigolo, S., Filippi, L., Laporta, M. \& Piva, G. 2009. On the occurrence of aflatoxin M1 in milk and dairy products. Food and Chemical Toxicology. 47: 984-991.

Gobierno de la República de Costa Rica. 2007. Reglamento Técnico: RTCR: 401-2006. Leche cruda y Leche Higienizada. La Gaceta $\mathrm{N}^{\circ} 112$. Jun 12 , San José.

Reyes, J.E., García, M.G. \& Hernández, L.A. 2011. Aplicación de los conceptos de inocuidad en la producción de leche en Sinaloa. Fundación PRODUCE, SAGARPA, Gobierno del Estado de Sinaloa.

Serraino, A. \& Giacometti, F. 2014. Short communication: Occurrence of Arcobacter species in industrial dairy plants. J. Dairy Sci. 97: 2061-2065. doi:10.3168/jds.2013-7682.

Stabel, J.R., Bradner, L., Robbe-Austerman, S. \& Beitz, D.C. 2014. Clinical disease and stage of lactation influence shedding of Mycobacterium avium subspecies paratuberculosis into milk and colostrum of naturally infected dairy cows. J. Dairy Sci. 97: 6296-6304. doi: 10.3168/jds.2014-8204.

Villoch, A. 2010. Buenas prácticas agropecuarias para la producción de leche. Sus objetivos y relación con los códigos de higiene. Rev. Salud Anim. 32 (3): 137-145.

Yang, B., Zhao, H., Cui, S., Wang, Y., Xia, X., Xi, M., Wang, X., Meng, J. \& Ge, W. 2014. Prevalence and characterization of Salmonella enterica in dried milk-related infant foods in Shaanxi, China. J. Dairy Sci. 97: 6754-6760. doi: 10.3168/jds.2014-8292. 